\title{
Liver fluke (Fasciola hepatica) naturally infecting introduced European brown hare (Lepus europaeus) in northern Patagonia: phenotype, prevalence and potential risk
}

\author{
Pablo F. Cuervo ${ }^{1 *}$, Sophia Di Cataldo ${ }^{1}$, M. Cecilia Fantozzi1 ${ }^{1}$ Erika Deis ${ }^{1}$, Gabriela Diaz Isenrath², \\ Gabriela Viberti ${ }^{3}$, Patricio Artigas ${ }^{4}$, Raquel Peixoto ${ }^{4}$, M. Adela Valero ${ }^{4}$, \\ Roberto Mera y Sierra ${ }^{1}$ and Santiago Mas-Coma ${ }^{4}$
}

${ }^{1}$ Centro de Investigación en Parasitología Regional, Facultad de Ciencias Veterinarias y Ambientales, Universidad Juan A. Maza. Av. Acceso Este, Lat. Sur 2245, Guaymallén, Mendoza, Argentina. Postal Code 5519; ${ }^{2}$ Facultad de Ciencias Exactas y Naturales, Universidad Nacional de Cuyo. Campus Educativo Municipal Malargüe. Malargüe, Mendoza, Argentina;

${ }^{3}$ Instituto Superior del Profesorado San Pedro Nolasco, Universidad del Aconcagua, Mendoza, Argentina; ${ }^{4}$ Departamento de Parasitología, Facultad de Farmacia, Universidad de Valencia. Av. Vicent Andrés Estellés s/n, 46100 Burjassot, Valencia, Spain

\begin{abstract}
Fascioliasis has recently been included in the WHO list of Neglected Zoonotic Diseases. Besides being a major veterinary health problem, fascioliasis has large underdeveloping effects on the human communities affected. Though scarcely considered in fascioliasis epidemiology, it is well recognized that both native and introduced wildlife species may play a significant role as reservoirs of the disease. The objectives are to study the morphological characteristics of Fasciola hepatica adults and eggs in a population of Lepus europaeus, to assess liver fluke prevalence, and to analyze the potential reservoir role of the European brown hare in northern Patagonia, Argentina, where fascioliasis is endemic. Measures of $F$. hepatica found in L. europaeus from northern Patagonia demonstrate that the liver fluke is able to fully develop in wild hares and to shed normal eggs through their faeces. Egg shedding to the environment is close to the lower limit obtained for pigs, a domestic animal whose epidemiological importance in endemic areas has already been highlighted. The former, combined with the high prevalence found (14.28\%), suggest an even more important role in the transmission cycle than previously considered. The results obtained do not only remark the extraordinary plasticity and adaptability of this trematode species to different host species, but also highlight the role of the European brown hare, and other NIS, as reservoirs capable for parasite spillback to domestic and native cycle, representing a potentially important, but hitherto neglected, cause of disease emergence.
\end{abstract}

\section{Keywords}

Fasciola hepatica, Lepus europaeus, introduced species, reservoir

\section{Introduction}

Fascioliasis, traditionally considered as a veterinary health problem (Kaplan 2001), has recently been included in the World Health Organization list of Neglected Zoonotic Diseases (NZDs). This consideration is due to its emergence and re-emergence worldwide, affecting an estimated 17 million people (Mas-Coma et al. 2009), in a phenomenon which has partly been related to climate change (Mas-Coma et al. 2008;
Afshan et al. 2014), and to the long-term pathogenic impact of this disease (Mas-Coma et al. 2014a). True human endemic areas have recently been described in which fascioliasis chronicity and superimposed repetitive infections pose pathological complications, indicating this disease to have large underdeveloping effects on the human communities affected (Valero et al. 2003, 2006a, 2008).

Fasciolid flukes follow a two-host life cycle, including a less specific adult stage which develops in many species of 
herbivorous mammals and even in a few omnivorous ones, and highly specific larval stages which only develop in given freshwater snail species of the family Lymnaeidae (Bargues and Mas-Coma 2005). With regard to the infection of animal reservoirs, the infectivity of the metacercarial infective stage from different animal species isolates has experimentally shown to be similar (Valero and Mas-Coma 2000; Valero et al. 2001a, 2011). Hence, the importance of ascertaining which animal species, including both domestic and sylvatic, develop a reservoir role in an endemic area.

Argentina presents a very widely distributed veterinary problem of fascioliasis in livestock (Olaechea 2007). Additionally, a recent analysis highlights that human fascioliasis in the country may have been overlooked in the past and its real epidemiological situation may currently be underestimated (Mera y Sierra et al. 2011). Surprisingly, geographical distribution of human infection does not fit that of fascioliasis in livestock, suggesting other transmission and epidemiological factors to be involved (Mera y Sierra et al. 2011).

Though scarcely considered, it is known that wildlife species may play a significant role as reservoirs of fascioliasis (Mas-Coma et al. 1988; Daszak et al. 2000; Bengis et al. 2004; Kruse et al. 2004; Polley 2005; Gayo et al. 2011; Mezo et al. 2013). Introduced non-indigenous species (NIS) are widely recognized as a source of disease (Daszak et al. 2000; Kelly et al. 2009). The importance and consequences of the introduction of NIS in fascioliasis has been the subject of several analyses, concerning both lymnaeids (Mas-Coma et al. 2003, 2005, 2009; Bargues and Mas-Coma 2005) and animal reservoirs (Mas-Coma et al. 2009).

Introduced into South America at the end of 19th century, the European brown hare (Lepus europaeus) represents one of the most widespread species of mammals (Bonino et al. 2010). The species has invaded almost all the extension of Argentina, Chile and Uruguay, and southern regions of Peru, Bolivia, Paraguay, and Brazil (Bonino et al. 2010). Despite old reports of $F$. hepatica in lagomorphs in general (Arru et al. 1967) and especifically infecting the hare in its original home range (Tropilo 1964; Kutzer and Frey 1976; Nickel and Gottwald 1979; Shimalov 2001; Ziege et al. 2009; Walker et al. 2011), the latter has been rarely considered in the epidemiology of the disease, particularly with regard to South American introduced populations. Additionally, phenotypic descriptions of adults and eggs of $F$. hepatica infecting natural populations of $L$. europaeus are lacking in the Neotropical region and even scarce worldwide.

The aims of the present article are to study the morphological characteristics of parasite adults and eggs in a population of L. europaeus in the northernmost part of Patagonia region (Argentina), to assess liver fluke prevalence and to analyze the potential reservoir role of this wild lagomorph in an area where fascioliasis is known to occur in livestock (Sidoti et al. 2009).

\section{Materials and Methods}

\section{Host materials}

Specimens of the European brown hare were obtained from the outskirts of Malargüe city (Mendoza province, Argentina), within the northernmost unit (Payunia district) of the Central Patagonia biogeographic province (Morrone 2006). Animals were captured by local hunters between August and September 2010 , in an area of a mean altitude around 1500 m.a.s.1. A total of 35 refrigerated intestinal tracts and 27 livers were received for parasitological examination.

\section{Parasitological techniques}

Refrigerated intestinal tracts were immediately inspected for helminths, while faeces and livers were preserved in formaldehyde $4 \%$ for later examination. The content from the gas-

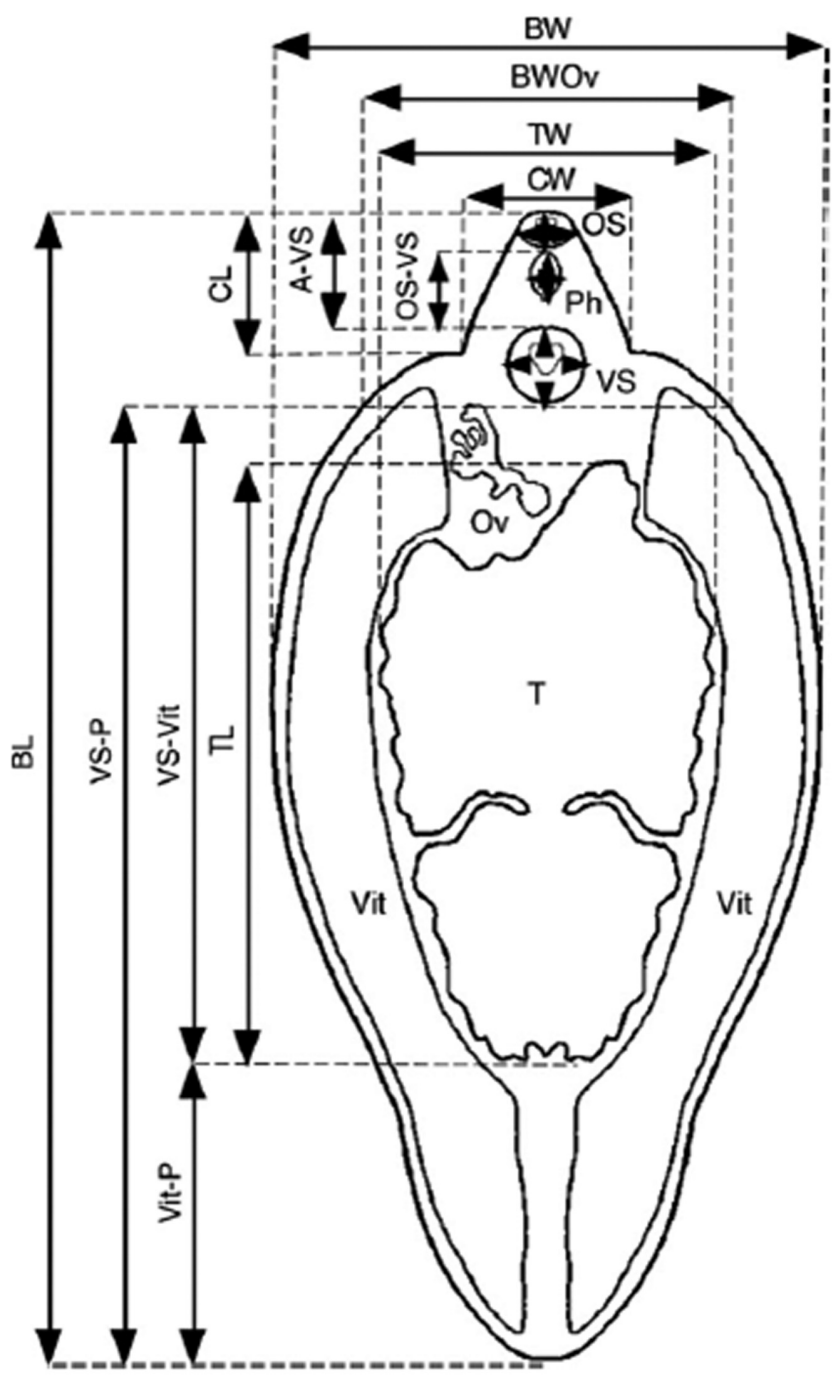

Fig. 1. Standardised measurements in gravid adults of Fasciola hepatica 


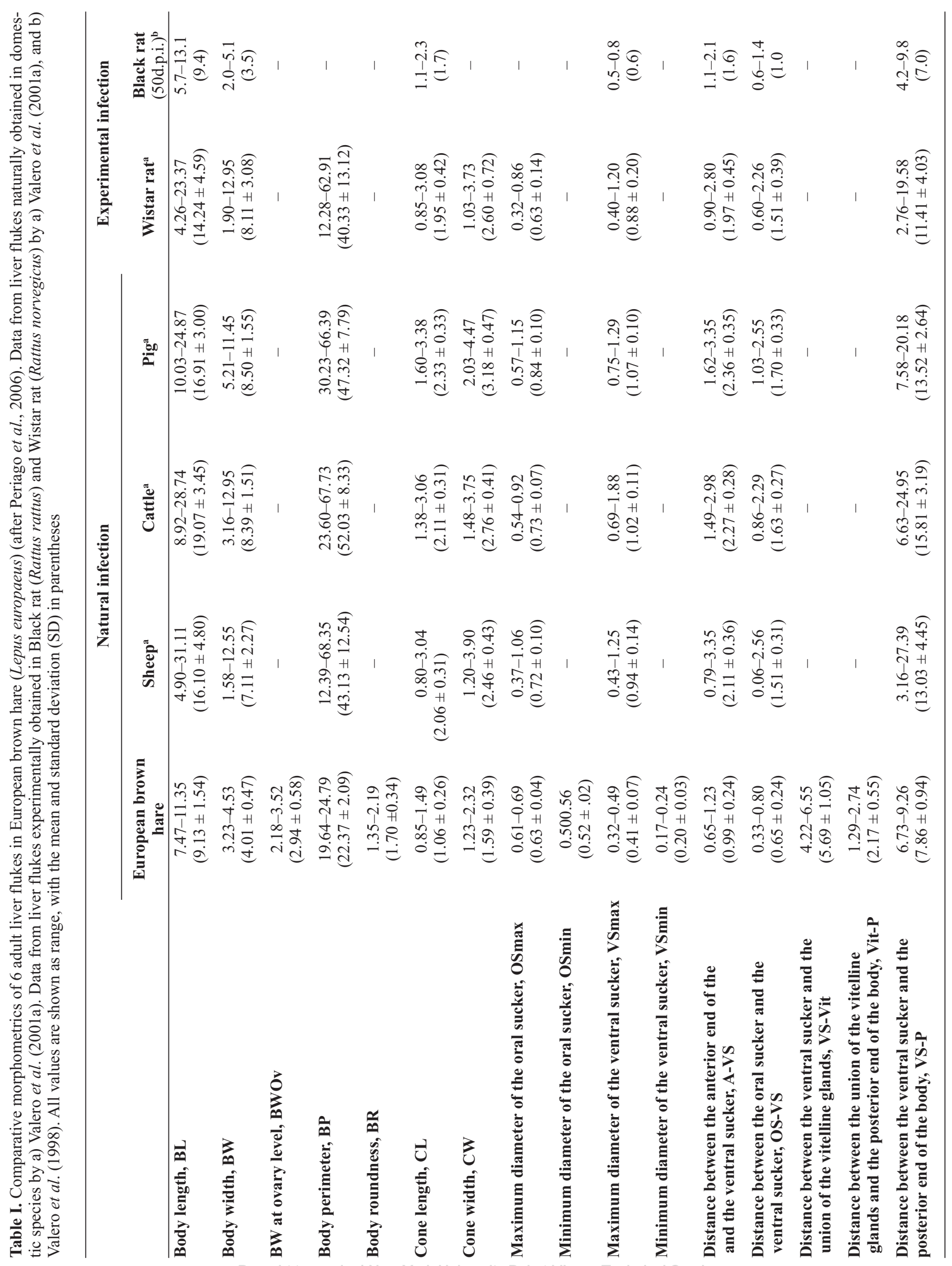




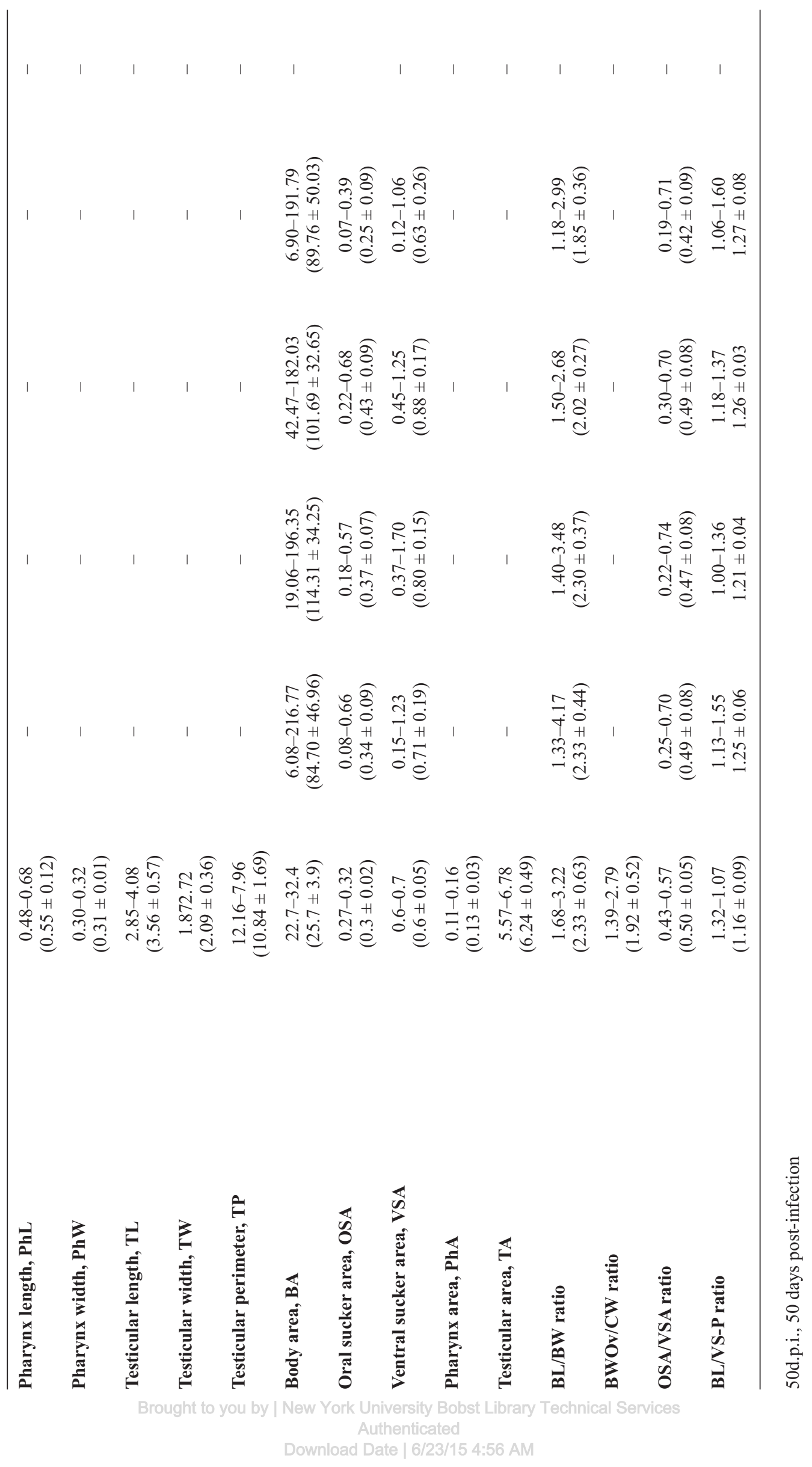


Table II. Measurements taken from 280 eggs of Fasciola hepatica, recovered from faeces of European brown hare (Lepus europaeus). All values are shown as range, with the mean and standard deviation (SD) in parentheses. EL, egg length ( $\mu \mathrm{m})$; EW, egg width ( $\mu$ m); EA, egg area $\left(\mu \mathrm{m}^{2}\right)$, ER, egg ratio; n.i., natural infection; e.i., experimental infection. Data from rodents and other domestic species by a) Valero et al. (2002), and b) Valero et al. (2001a)

\begin{tabular}{|c|c|c|c|c|c|}
\hline Host & Geographical location & $\mathbf{E L}$ & $\mathbf{E W}$ & EA & ER \\
\hline Black rat (Rattus rattus), n.i. ${ }^{a}$ & $\begin{array}{l}\text { Corsica island, } \\
\text { Mediterranean Sea }\end{array}$ & $\begin{array}{c}122-148 \\
(133 \pm 8)\end{array}$ & $\begin{array}{c}60-74 \\
(67 \pm 3)\end{array}$ & $\begin{array}{c}7148-10344 \\
(9011 \pm 685)\end{array}$ & - \\
\hline Cattle (Bos Taurus), n.i. ${ }^{\mathrm{b}}$ & Northern Bolivian Altiplano & $\begin{array}{c}105.3-155.9 \\
(132.0 \pm 10.5)\end{array}$ & $\begin{array}{c}61.7-82.5 \\
(71.1 \pm 4.4)\end{array}$ & $\begin{array}{c}5286.5-9676.8 \\
(7170.2 \pm 802.5)\end{array}$ & $\begin{array}{c}1.6-2.3 \\
(1.9 \pm 0.2)\end{array}$ \\
\hline Sheep (Ovis aries), n.i. ${ }^{\mathrm{b}}$ & Northern Bolivian Altiplano & $\begin{array}{c}114.8-151.2 \\
(130.8 \pm 7.1)\end{array}$ & $\begin{array}{c}65.5-81.4 \\
(72.6 \pm 3.9)\end{array}$ & $\begin{array}{c}5998.2-8608.5 \\
(7238.0 \pm 532.8)\end{array}$ & $\begin{array}{c}1.5-2.2 \\
(1.8 \pm 0.1)\end{array}$ \\
\hline Wistar rat (Rattus norvegicus), e.i. ${ }^{\mathrm{a}}$ & $\begin{array}{l}\text { Corsica island, } \\
\text { Mediterranean Sea }\end{array}$ & $\begin{array}{c}122-148 \\
(134 \pm 6)\end{array}$ & $\begin{array}{c}63-80 \\
(70 \pm 4)\end{array}$ & $\begin{array}{l}7681-11841 \\
9376 \pm 866)\end{array}$ & - \\
\hline Wistar rat (Rattus norvegicus), e.i. ${ }^{\mathrm{b}}$ & Northern Bolivian Altiplano & $\begin{array}{c}98.1-144.2 \\
(124.6 \pm 7.8)\end{array}$ & $\begin{array}{c}56.9-80.8 \\
(67.6 \pm 3.4)\end{array}$ & $\begin{array}{c}4836.2-7982.3 \\
(6380.1 \pm 510.8)\end{array}$ & $\begin{array}{c}1.4-2.2 \\
(1.9 \pm 0.2)\end{array}$ \\
\hline
\end{tabular}

trointestinal tracts from each hare were thoroughly examined following standard methods (Egerton et al. 1979).

Previously preserved faecal samples were analyzed by means of two methods: Sheather's sucrose flotation technique (MacPherson and McQueen 1993) and Lumbreras' rapid sedimentation technique (Lumbreras et al. 1962). Sediment obtained from Lumbrera's technique was subsequently passed through a $140 \mu \mathrm{m}$ sieve. Both techniques were performed with three grams of material. Slides from Sheather's technique and filtered sediment from Lumbrera's technique were microscopically examined. Faecal counts (eggs per gram = epg; oocysts per gram $=$ opg) were determined in every sample.

Liver fluke adults were recovered from preserved livers, while eggs were concentrated by means of sedimentation and filtration from the remaining faecal material previously found 'positive'. Adult worms were stained with Grenacher's borax carmine and mounted in Canada balsam between slide and coverglass but without coverglass pressure (Valero et al. 2005, 2012).

\section{Measurement techniques and data analysis}

Egg characteristics studied were length (EL) and width (EW) in $\mu \mathrm{m}$. The product of these 2 dimensions was used as a measure of egg size $\left(E L \times E W=E S \mu m^{2}\right)$, and the ratio as a measure of shape $(E L / E W=E R)($ Poulin 1997; Abrous et al. 1998; Valero et al. 1998, 2001a, 2002). For egg classification, egg size was considered according to recent updates on this characteristic (Valero et al. 2009; Mas-Coma et al. 2014b), and by taking into account the influence of the host species (Valero et al. 1998, 2001a, 2002),

For adult fasciolids, the following standardized measurements were taken (Valero et al. 2005; Periago et al. 2006) (Fig. 1): (i) lineal biometric characters (mm): body length (BL), maximum body width (BW), body width at ovary level (BWOv), body perimeter (BP), body roundness (BR), cone length $(\mathrm{CL})$, cone width $(\mathrm{CW})$, maximum diameter of oral sucker (OS max), minimum diameter of oral sucker (OS min), maximum diameter of ventral sucker (VS max), minimum diameter of ventral sucker (VS min), distance between the anterior end of the body and ventral sucker (A-VS), distance between the oral sucker and ventral sucker (OS-VS), distance between the oral sucker and the union of the vitelline glands (VS-Vit), distance between the union of the vitelline glands and the posterior end of the body (Vit-P), distance between the ventral sucker and the posterior end of the body (VS-P), pharynx length $(\mathrm{PhL})$, pharynx width $(\mathrm{PhW})$, testicular space (taking both testes together) length (TL), testicular space width (TW), testicular space perimeter (TP); (ii) areas $\left(\mathrm{mm}^{2}\right)$ : body area (BA), oral sucker area (OSA), ventral sucker area (VSA), pharynx area (PhA), testicular space area (taking both testes together, TA); (iii) ratios: body length over body width (BL/BW), body width at ovary level over cone width $(\mathrm{BWOv} / \mathrm{CW})$, oral sucker area over ventral sucker area 
(OSA/VSA), and body length over the distance between the ventral sucker and the posterior end of the body (BL/VS-P).

Morphometric measurements used for $F$. hepatica adults follow a logistic growth model with respect to time (Valero et al. 2001a,b, 2005). This implies that the morphometric development of the fasciolid adult is not limited but 'damped' and does not exceed certain characteristic maximum (Valero et al. 1998, 2006b). Since the morphometric maximum values are characteristic for each population, they are considered the comparative base of this study (Table I).

\section{Results}

Five faecal samples were detected positive to Fasciola hepatica $(14.28 \%, 2.7-25.8 \%$ CI 0.95$)$, while 33 showed Eimeria sp. oocysts $(94.28 \%, 86.61-100 \%$ CI 0.95$)$. No nematode and cestode eggs or adults were observed. Faecal counts showed between 1 and 3 epg for liver fluke (mean $2.08 \mathrm{epg}, \pm 1.25$ ), and 91.73 mean opg $( \pm 155.84)$ for Eimeria sp.

Twenty-two liver fluke adults were recovered from a single liver, but only six of them could be measured (Table I), while a total of 280 eggs were recovered from faeces and measured (Table II).

\section{Discussion}

Each trematode species has its own adult and egg phenotype, generally within a specific range (Valero et al. 2009). However, small host body mass offers limited microhabitat (e.g. liver) and places a physical constraint upon the trematode body size and number of flukes that can fit in (Poulin 1997; Valero et al. 2001a, 2005); while it has been associated with diminished egg size (Valero et al. 2002). Consequently, the final host species decisively influences the size of adults and eggs of F. hepatica (Valero et al. 2001a,b, 2005, 2009).

Measures of $F$. hepatica found in L. europaeus from Malargüe department proved to be among the smaller described in adults and eggs recovered from naturally and experimentally infected murid rodents, lagomorphs and domestic species (see Tables I and II) (Abrous et al. 1998; Valero et al. 1998, 2001a, 2002). With regard to adult liver flukes, it shall be considered that samples were preserved in formaldehyde $4 \%$ during, at least, two months, which might have slightly decreased measures. Size of the fasciolids from the European brown hare appears similar to fasciolids of 50 days of age experimentally obtained in the Black rat (Valero et al. 1998) (Table I). However, the size of $F$. hepatica eggs found in faecal samples of the hares fully overlap not only with those of natural and experimental infections in murid rodents, but also with those of natural infections in cattle and other domestic animals (Valero et al. 2001a, 2002). All in all, the data obtained indicates that the liver fluke is able to fully develop in wild hares and to shed normal eggs through their faeces.
Additionally, the heavy parasite burden observed (22 liver flukes in a single liver) and the small adult size described strongly suggest an effect of crowding, a phenomenon reflected in a decreased adult development when the number of flukes is high (Valero et al. 2006b). Meanwhile, due to experimental evidence of a direct relation between uterus size and the numbers of eggs shed per gram of faeces (Valero et al. 2001b, 2011), the reduced uterus development as consequence of smaller adults (Poulin 1997) may explain the low epg observed.

Although $F$. hepatica infection in wild $L$. europaeus has been detected before in its original European range, to the best of our knowledge only one report deals with that aspect in South America (Kleinman et al. 2004). Unfortunately, the information provided is only restricted to the local prevalence found. The high prevalence found in our study $(14.28 \%, 2.7$ $25.8 \%$ CI 0.95$)$ strongly contrasts with the very low one registered $(<1 \%$ ) in the aforementioned study (Kleiman et al. 2004). Our results suggest an even more important role in the transmission cycle than previously considered, at least in given areas.

Considering a daily defaecation rate of 410 faecal pellets per hare (Novaro et al. 1992), a pellet weight between 1 and $1.4 \mathrm{gr}$ (Kleiman et al. 2004), and the epg here obtained, each hare could shed to the environment a daily rate of 410-1,722 eggs of $F$. hepatica. This result is close to the lower limit obtained for pigs (2,000-195,000 eggs/individual/day), a domestic animal whose epidemiological importance in endemic areas has already been highlighted (Mas-Coma et al. 1997, 2005).

Parasites tend to have threshold levels of host populations size below which they are unable to persist (Tompkins and Poulin 2006). The population dynamics of the European brown hare, as a competent host for liver fluke (i.e. hosts in which the parasites can develop normally), may allow parasite spillback by amplifying the total number of infective stages and increasing the infection burdens in populations of other susceptible hosts (native or domestic) (Kelly et al. 2009; Poulin et al. 2011). This situation set the stage for the European brown hare, a NIS, to alter local parasite dynamics in ways that could lead to disease emergence and an outbreak (Rachowicz et al. 2005; Thieltges et al. 2009; Poulin et al. 2011).

The results obtained do not only remark the extraordinary plasticity and adaptability of this trematode species to different host species, but also highlight the role of the European brown hare, and other NIS, as reservoirs capable for parasite spillback to domestic and native cycle, representing a potentially important, but hitherto neglected, cause of disease emergence. The present finding of $F$. hepatica in hares indicates that the geography of the populations of this lagomorph will be in need to be considered when analysing the distribution and extent of fascioliasis infection risk areas (Fuentes et al. 1999, 2001; Afshan et al. 2014) in Argentina and also in other South American endemic countries where the European hare has been introduced. 


\section{References}

Abrous M., Comes A.M., Gasnier N., Rondelaud D., Dreyfuss G., Chauvin A., Ménard A., Agoulon A., Cabaret, J. 1998. Morphological variability in Fasciola hepatica eggs in ruminants, rodents and lagomorphs. Journal of Helminthology 72, 313317. DOI: $10.1017 / \mathrm{S} 0022149$ X00016667

Afshan K., Fortes-Lima C.A., Artigas P., Valero M.A., Qayyum M., Mas-Coma, S. 2014. Impact of climate change and man-made irrigation systems on the transmission risk, long-term trend and seasonality of human and animal fascioliasis in Pakistan. Geospatial Health 8, 317-334. DOI: 24893010

Arru E., Deiana S., Nuvole A. 1967. Distomatosi epatica nei leporidi selvatici in Sardegna. Atti della Societa Italiana delle Scienze Veterinaria 21, 762-766

Bargues M.D., Mas-Coma S. 2005. Reviewing lymnaeid vectors of fascioliasis by ribosomal DNA sequence analyses. Journal of Helminthology 79, 257-267. DOI: 10.1079/JOH2005297

Bengis R.G., Leighton F.A., Fischer J.R., Artois M., Mörner T., Tate C. M. 2004. The role of wildlife in emerging and re-emerging zoonoses. Revue Scientifique et Technique - Office International des Epizooties 23, 497-511

Bonino N., Cossios D., Meneghetti J. 2010. Dispersal of the European hare, Lepus europaeus in South America. Folia Zoologica 59, 9-15

Daszak P., Cunningham A.A., Hyatt A.D. 2000. Emerging infectious diseases of wildlife - Threats to biodiversity and human health. Science 287, 443-449. DOI: 10.1126/science.287. 5452.443

Egerton J.R., Ostlind D.A., Blair L.S., Eary C.H., Suhayda D., Cifelli S., Riek R.F., Campbell W.C. 1979. Avermectins, new family of potent anthelmintic agents: efficacy of the B1a component. Antimicrobial Agents and Chemotherapy 15, 372-378

Fuentes M.V., Valero M.A., Bargues M.D., Esteban J.G., Angles R., Mas-Coma S. 1999. Analysis of climatic data and forecast indices for human fascioliasis at very high altitude. Annals of Tropical Medicine and Parasitology 93, 835-850

Fuentes M.V., Malone J.B., Mas-Coma S. 2001. Validation of a mapping and predicting model for human fasciolosis transmission in Andean very high altitude endemic areas using remote sensing data. Acta Tropica 79, 87-95. DOI: 10.1016/S0001-706X (01)00106-1

Gayo V., Cuervo P., Rosadilla D., Birriel S., Dell'Oca L., Trelles A., Cuore U., Mera y Sierra R. 2011. Natural Fasciola hepatica infection in "Nutria" (Myocastor coypus), in Uruguay. Journal of Zoo and Wildlife Medicine 42, 354-356. DOI: 10. 1638/2010-0226.1

Kaplan R.M. 2001. Fasciola hepatica: a review of the economic impact in cattle and considerations for control. Veterinary Therapeutics 2, 40-50

Kelly D.W., Paterson R.A., Townsend C.R., Poulin R., Tompkins D.M. 2009. Parasite spillback: a neglected concept in invasion ecology? Ecology 90, 2047-2056. DOI: 10.1890/081085.1

Kleinman F., González N., Rubel D., Wisnivesky C. 2004. Fasciola hepatica (Linnaeus, 1758) (Trematoda, Digenea) en liebres europeas (Lepus europaeus, Pallas 1778) (Lagomorpha, Leporidae) en la región Cordillerana Patagónica, Chubut, Argentina. Parasitología Latinoamericana 59, 68-71. DOI: 10.4067/S0717-77122004000100014

Kruse H., Kirkemo A., Handeland K. 2004. Wildlife as source of zoonotic infections. Emerging Infectious Diseases 10, 2067 2072. DOI: 10.3201/eid1012.040707.

Kutzer E., Frey H. 1976. Die Parasiten der Feldhasen (Lepus europaeus) in Österreich. (Parasites of the European brown hare in Austria). Berliner und Münchener Tierärztliche Wochenschrift 89, 480-483

Lumbreras H., Cantella R., Burga R. 1962. Acerca de un procedimiento de sedimentación rápida para investigar huevos de Fasciola hepatica en las heces, su evaluación y uso en el campo. Revista Médica Peruana 31, 167-174

MacPherson D.W., McQueen R. 1993. Cryptosporidiosis: multiattribute evaluation of six diagnostic methods. Journal of Clinical Microbiology 31, 198-202

Mas-Coma S., Fons R., Feliu C., Bargues M.D., Valero M.A., GalanPuchades M.T. 1988. Small mammals as natural definitive hosts of the liver fluke, Fasciola hepatica Linnaeus, 1758 (Trematoda: Fasciolidae): a review and two new records of epidemiologic interest on the island of Corsica. Rivista di Parasitologia $5,73-78$

Mas-Coma S., Rodriguez A., Bargues M.D., Valero M.A., Coello J.R., Angles R. 1997. Secondary reservoir role of domestic animals other than sheep and cattle in fascioliasis transmission in the Northern Bolivian Altiplano. Research and Reviews in Parasitology 57, 39-46

Mas-Coma S., Bargues M.D., Valero M.A., Fuentes M.V. 2003. Adaptation capacities of Fasciola hepatica and their relationships with human fascioliasis: from below sea level up to the very high altitude. In: (Eds. C. Combes and J. Jourdane) Taxonomy, Ecology and Evolution of Metazoan Parasites, Perpignan, France, Presses Universitaires de Perpignan, 81-123

Mas-Coma S., Bargues M.D., Valero M. A. 2005. Fascioliasis and other plant-borne trematode zoonoses. International Journal for Parasitology 35, 1255-1278. DOI:10.1016/j.ijpara.2005. 07.010

Mas-Coma S., Valero MA., Bargues MD. 2008. Effects of climate change on animal and zoonotic helminthiases. Revue Scientifique et Technique - Office International des Epizooties 27, 443-457

Mas-Coma S., Valero M. A., Bargues M. D. 2009. Fasciola, lymnaeids and human fascioliasis, with a global overview on disease transmission, epidemiology, evolutionary genetics, molecular epidemiology and control. Advances in Parasitology 69, 41-146. DOI: 10.1016/S0065-308X(09)69002-3

Mas-Coma S., Agramunt V.H., Valero M.A. 2014a. Neurological and ocular fascioliasis in humans. Advances in Parasitology 84, 27-149. DOI: 10.1016/B978-0-12-800099-1.00002-8

Mas-Coma S., Bargues M.D., Valero M.A. 2014b. Diagnosis of human fascioliasis by stool and blood techniques: Update for the present global scenario. Parasitology, 141 (Special Issue), 1918-1946. DOI: 10.1017/S0031182014000869

Mera y Sierra R., Agramunt V.H., Cuervo P., Mas-Coma S. 2011. Human fascioliasis in Argentina: retrospective overview, critical analysis and baseline for future research. Parasites and Vectors 4, 104. DOI: 10.1186/1756-3305-4-104

Mezo M., González-Warleta M., Castro-Hermida J.A., Manga-González M.Y., Peixoto R., Mas-Coma S., Valero M.A. 2013. The wild boar (Sus scrofa Linnaeus, 1758) as secondary reservoir of Fasciola hepatica in Galicia (NW Spain). Veterinary Parasitology 198, 274-283. DOI: 10.1016/j.vetpar.2013.09.009

Morrone J.J. 2006. Biogeographic areas and transition zones of Latin America and the Caribbean islands based on pangeographic and cladistic analyses of the entomofauna. Annual Review of Entomology 51, 467-494. DOI: 10.1146/annurev.ento.50.07 1803.130447

Nickel S., Gottwald A. 1979. Parasites of the GDR. 3. Endoparasites of the hare (Lepus europeus). Angewandte Parasitologie, 20, $57-62$

Novaro A.J., Capurro A.F., Travaini A., Funes M.C., Rabinovich J.E. 1992. Pellet-count sampling based on spatial distribution: a case study of the European hare in Patagonia. Ecología Austral 2, 11-18 
Olaechea F. V. 2007. Tremátodes y Céstodes: Fasciola hepatica. In: (Eds. V. H. Suárez, F. V. Olaechea, C. E. Rossanigo, and J. R. Romero), Enfermedades parasitarias de los ovinos y otros rumiantes menores en el cono sur de América, Buenos Aires, Argentina, Instituto Nacional de Tecnología Agropecuaria INTA-, 159-168

Periago M.V., Valero M.A., Panova M., Mas-Coma S. 2006. Phenotypic comparison of allopatric populations of Fasciola hepatica and Fasciola gigantica from European and African bovines using a computer image analysis system (CIAS). Parasitology Research 99, 368-378. DOI: 10.1007/s00436-0060174-3

Polley L. 2005. Navigating parasite webs and parasite flow: Emerging and re-emerging parasitic zoonoses of wildlife origin. International Journal for Parasitology 35, 1279-1294. DOI: 10.1016/j.ijpara.2005.07.003

Poulin R. 1997. Egg production in adult trematodes: adaptation or constraint. Parasitology 11, 195-204. DOI: 10.1017/S00 31182096008372

Poulin R., Paterson R.A., Townsend C.R., Tompkins D.M., Kelly D.W. 2011. Biological invasions and the dynamics of endemic diseases in freshwater ecosystems. Freshwater Biology 56, 676-688. DOI: 10.1111/j.1365-2427.2010.02425.x

Rachowicz L.J., Hero J.M., Alford R.A., Taylor J.W., Morgan J.A.T., Vredenburg V.T., Collins J.P., Briggs C.J. 2005. The novel and endemic pathogen hypotheses: competing explanations for the origin of emerging infectious diseases of wildlife. Conservation Biology 19, 1441-1448. DOI: 10.1111/j.1523-1739. 2005.00255.x

Shimalov V.V. 2001. Helminth fauna of the hare (Lepus europaeus Pallas, 1778) in the southern part of Belarus. Parasitology Research 87, 85. DOI: $10.1007 / \mathrm{s} 004360000259$

Sidoti L., Mera y Sierra R.L., Cuervo P., Micó M., Bargues M.D., Mas-Coma S., Artigas P. 2009. Sheep and goat fascioliasis in the Mendoza province, Argentina. Acta Parasitologica Portuguesa $16,112-113$

Thieltges D.W., Reise K., Prinz K., Jensen K.T. 2009. Invaders interfere with native parasite-host interactions. Biological Invasions 11, 1421-1429. DOI: 10.1007/s10530-008-9350-y

Tompkins D.M., Poulin R. 2006. Parasites and biological invasions. In: (Eds. R. B. Allen, and W. G. Lee), Biological Invasions in New Zealand, Heidelberg, Berlin, Germany, Springer, 67-86

Tropilo J. 1964. Intensity and extensity of invasion by Cysticercus pisiformis and Fasciola hepatica in hares (in Polish). Medycyna Weterynaryjna Warszawa 20, 259-269

Valero M.A., Mas-Coma S. 2000. Comparative infectivity of Fasciola hepatica metacercariae from isolates of the main and secondary reservoir animal host species in the Bolivian Altiplano high human endemic region. Folia Parasitologica 47, 17-22

Valero M.A., Marcos M.D., Fons R., Mas-Coma S. 1998. Fasciola hepatica development in the experimentally infected black rat Rattus rattus. Parasitology Research 84, 188-194. DOI: $10.1007 / \mathrm{s} 004360050381$

Valero M.A., Darce N.A., Panova M., Mas-Coma S. 2001a. Relationships between host species and morphometric patterns in Fasciola hepatica adults and eggs from the northern Bolivian Altiplano hyperendemic region. Veterinary Parasitology 102 , 85-100. DOI: 10.1016/S0304-4017(01)00499-X
Valero M.A., Panova M., Mas-Coma S. 2001b. Developmental differences in the uterus of Fasciola hepatica between livestock liver fluke populations from Bolivian Highlands and European lowlands. Parasitology Research 87, 337-342. DOI: 10.1007/PL00008588

Valero M.A., Panova M., Comes A.M., Fons R., Mas-Coma S. 2002. Patterns in size and shedding of Fasciola hepatica eggs by naturally and experimentally infected murid rodents. Journal of Parasitology 88, 308-313. DOI: 10.1645/0022-3395(2002) 088[0308:PISASO]2.0.CO;2

Valero M. A., Santana M., Morales M., Hernandez J. L., Mas-Coma S. 2003. Risk of gallstone disease in advanced chronic phase of fascioliasis: an experimental study in a rat model. Journal of Infectious Diseases 188, 787-793. DOI: 10.1086/377281

Valero M. A., Panova M., Mas-Coma S. 2005. Phenotypic analysis of adults and eggs of Fasciola hepatica by computer image analysis system. Journal of Helminthology 79, 217-225. DOI: 10.1079/JOH2005301

Valero M.A., Navarro M., Garcia-Bodelon M.A., Marcilla A., Morales M., Garcia J.E., Hernandez J. L., Mas-Coma S. 2006a. High risk of bacterobilia in advanced experimental chronic fasciolosis. Acta Tropica 100, 17-23. DOI: 10.1016/j.actatropica.2006.09.002

Valero M. A., De Renzi M., Panova M., García-Bodelon M. A., Periago M. V., Ordoñez D., Mas-Coma S. 2006b. Crowding effect on adult growth, pre-patent period and egg sheding of Fasciola hepatica. Parasitology 133, 453-463. DOI: 10.1017/S003118200600059X

Valero M.A., Girones N., Garcia-Bodelon M.A., Periago M.V., Chico-Calero I., Khoubbane M., Fresno M., Mas-Coma S. 2008. Anaemia in advanced chronic fasciolosis. Acta Tropica 108, 35-43. DOI: 10.1016/j.actatropica.2008.08.007.

Valero M.A., Perez-Crespo I., Periago M.V., Khoubbane M., MasComa S. 2009. Fluke eggs characteristics for the diagnosis of human and animal fascioliasis by Fasciola hepatica and Fasciola gigantica. Acta Tropica 111, 150-159. DOI: 10.1016/ j.actatropica.2009.04.005

Valero M.A., Panova M., Pérez-Crespo I., Khoubbane M., MasComa S. 2011. Correlation between egg-shedding and uterus development in Fasciola hepatica human and animal isolates: applied implications. Veterinary Parasitology 183, 79-86. DOI: 10.1016/j.vetpar.2011.07.003

Valero M.A., Perez-Crespo I., Khoubbane M., Artigas P., Panova M., Ortiz P., Maco V., Espinoza J. R., Mas-Coma S. 2012. Fasciola hepatica phenotypic characterization in Andean human endemic areas: valley versus altiplanic patterns analysed in liver flukes from sheep from Cajamarca and Mantaro, Peru. Infection, Genetics and Evolution 12, 403-410. DOI: 10.1016/j.meegid.2012.01.009

Walker S.M., Johnston C., Hoey E.M., Fairweather I., Borgsteede F.H.M., Gaasenbeek C.P.H., Prodohl P.A., Trudgett A. 2011. Potential role of hares in the spread of liver fluke in the Netherlands. Veterinary Parasitology 177, 179-181. DOI: 10.1016/j.vetpar.2010.11.043

Ziege S., Brauneis M., von Keyserlingk M., Wohlsein P. 2009. Fasziolose beim Europäischen Feldhasen (Lepus europaeus) in Nordwestdeutschland. Deutsche Tierarztliche Wochenschrifte $116,60-63$

Received: December 13, 2014

Revised: February 24, 2015

Accepted for publication: April 17, 2015 